\title{
PERHITUNGAN DEBIT PADA SISTEM JARINGAN PIPA DENGAN METODA HARDY-CROSS MENGGUNAKAN RUMUS HASEN- WILLIAMS DAN RUMUS MANNING
}

\author{
Kanjalia Rusli $^{1}$, Agus Susanto ${ }^{2}$ \\ ${ }^{1}$ Dosen tetap Jurusan Teknik Sipil, Universitas Kristen Maranatha, Bandung \\ ${ }^{2}$ Alumnus Jurusan Teknik Sipil, Universitas Kristen Maranatha, Bandung
}

\begin{abstract}
ABSTRAK
Pemakaian jaringan pipa dalam bidang teknik sipil salah satunya terdapat pada sistem jaringan distribusi air minum. Analisis jaringan pipa cukup komplek dan memerlukan perhitungan yang besar. Adapun metoda yang digunakan adalah Metoda Hardy-Cross dalam menentukan debit pada masingmasing pipa. Metoda ini merupakan metoda yang paling banyak digunakan dalam melakukan analisis jaringan pipa. Dalam perhitungan ini digunakan rumus Hazen-Williams dan rumus Manning dalam menentukan nilai konsanta hambatan pipa $(\mathrm{k})$.

Akan dianalisis sebagian jaringan pipa PDAM di Kota Padalarang Kabupaten Bandung. Debit masuk pada jaringan ditentukan $30 \mathrm{lt} /$ det dan 10 lt/det sedangkan debit yang keluar 25 lt/det dan 15 lt/det, koefisien Hazen-Williams 142 dan koefisien Manning 0.011, menggunakan pipa PVC berdiameter 2" dan 3", kehilangan energi yang diperhitungkan hanya kehilangan energi primer. Kesimpulan yang diperoleh adalah penggunaan diameter pipa yang sama pada jaringan pipa akan menghasilkan debit tetap (tidak berubah), karena diameter pipa dapat saling meniadakan dalam perhitungan dan pada kasus yang debitnya besar (>10 lt/det) akan menghasilkan persentasi perbedaan debit $(\Delta \%)$ yang tidak jauh baik dengan rumus Hazel-Williams dan rumus Manning karena persentasi perbedaan debitnya kecil sehingga untuk debit yang besar (>10 lt/det) hasil lebih akurat, begitu pula sebaliknya.
\end{abstract}

Kata kunci: jaringan pipa, debit pada pipa, metoda Hardy-Cross

\section{PENDAHULUAN}

Di era pembangunan yang semakin pesat, pembangunan jaringan-jaringan pipa lebih banyak digunakan dalam berbagai keperluan. Hal ini karena pipa mempunyai kelebihan dibanding dengan sarana lain (saluran terbuka, pengangkutan dengan sarana transportasi), antara lain: jumlah kehilangan volume fluida lebih kecil, waktu penghantaran fluida lebih cepat dan tak terputus, fluida lebih terlindungi.

Melihat perkembangan yang semakin meningkat, kebutuhan terhadap air juga meningkat pada suatu komunitas yang besar. Kebutuhan akan air pada masing-masing keluarga berbeda-beda, sehingga dibutuhkan suatu sistem pendistribusian air yang baik. Jaringan pipa harus direncanakan sedemikian rupa sehingga debit yang dikeluarkan sesuai dengan permintaan. Kesalahan dalam perencanaan dan penghitungan dapat berakibat permintaan tidak terpenuhi.

Nilai konstanta hambatan pipa (k) pada Metoda Hardy-Cross di suatu jaringan pipa merupakan angka yang bergantung pada rumus gesekan pipa dan karakteristik pipa. Diperkirakan bahwa nilai konstanta hambatan pipa (k) ini juga menentukan dalam 
pembuatan jaringan-jaringan pipa.

Besarnya debit air pada masing-masing pipa dengan Metoda Hardy-Cross dalam suatu jaringan pipa tertentu juga untuk menentukan nilai debit optimum pada masing-masing pipa dalam suatu jaringan pipa.

Analisis sebagian jaringan pipa PDAM di Kota Padalarang dengan Metoda HardyCross menggunakan rumus Hazel-Williams dan rumus Manning dalam perhitungan konstanta hambatan pipa (k) dibatasi oleh hal-hal sebagai berikut:

a. Kehilangan energi yang diperhitungkan hanya kehilangan energi primer, sedangkan kehilangan energi sekunder tidak diperhitungkan.

b. Diameter pipa PVC yang digunakan adalah 2" dan 3".

c. Koefisien Hazel-Williams $\left(\mathrm{C}_{\mathrm{HW}}\right)=142$.

d. Koefisien Manning (n') $=0,011$.

e. Debit masuk $\left(\mathrm{Q}_{\text {masuk }}\right)=30 \mathrm{lt} / \mathrm{det}$ dan $10 \mathrm{lt} / \mathrm{det}$.

f. Debit keluar $\left(\mathrm{Q}_{\text {keluar }}\right)=15 \mathrm{lt} / \mathrm{det}$ dan $25 \mathrm{lt} / \mathrm{det}$.

\section{JARINGAN PIPA}

Sistem jaringan pipa yang akan dibahas adalah sebagian dari sistem jaringan pipa yang mengacu pada jaringan pipa distribusi air minum PDAM di Kota Padalarang, Bandung. Sistem jaringan pipa tersebut terdiri dari 6 titik simpul (nodal), 8 pipa dan 3 jaringan (loop). Bentuk jaringan pipa yang diambil adalah seperti terlihat pada gambar 1.

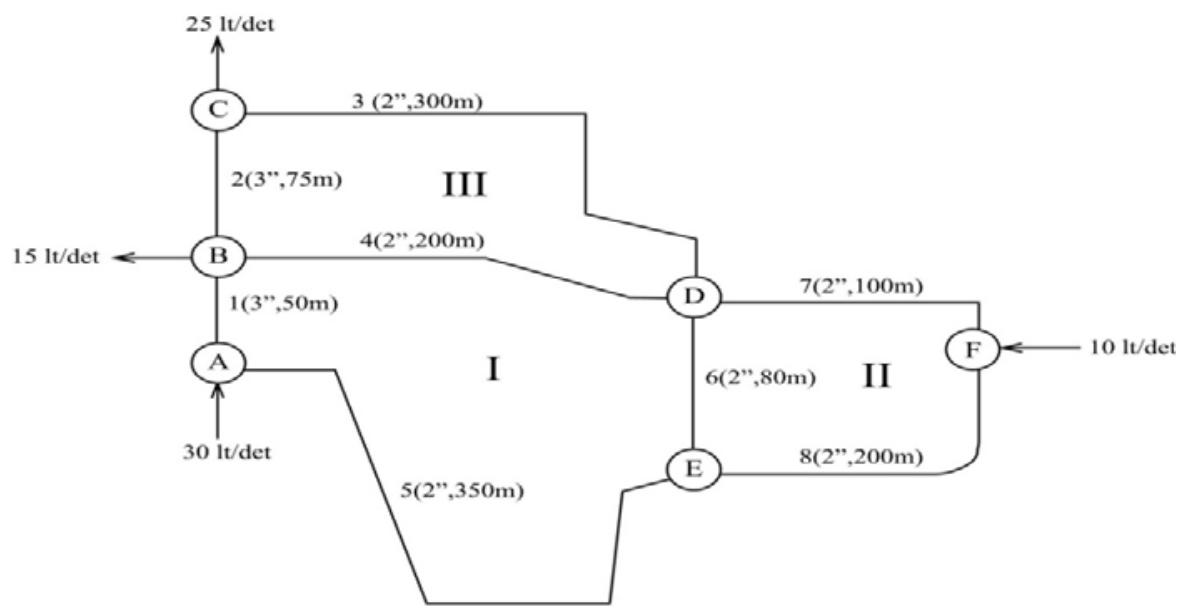

Gambar 1. Sebagian Jaringan PDAM di Kota Padalarang.

Adapun data dari sebagian jaringan pipa PDAM di Kota Padalarang adalah seperti terlihat di bawah ini:

Perhitungan Debit Pada Sistem Jaringan Pipa dengan Metode Hardy-Cross Menggunakan Rumus Hazen-Williams dan Rumus Manning 
Tabel 1.

\begin{tabular}{|c|c|c|c|c|c|c|}
\hline Pipa & Panjang & Kasus 1 & Kasus 2 & Kasus 3 & Kasus 4 & Kasus 5 \\
\cline { 3 - 7 } & (m) & Diameter & Diameter & Diameter & Diameter & Diameter \\
(in) & (in) & (in) & (in) \\
\hline $1(\mathrm{AB})$ & 50 & 3 & 2 & 3 & 2 & 3 \\
\hline $2(\mathrm{BC})$ & 75 & 3 & 2 & 3 & 2 & 3 \\
\hline $3(\mathrm{CD})$ & 300 & 2 & 2 & 3 & 3 & 2 \\
\hline $4(\mathrm{BD})$ & 200 & 2 & 2 & 3 & 3 & 2 \\
\hline $5(\mathrm{AE})$ & 350 & 2 & 2 & 3 & 3 & 2 \\
\hline $6(\mathrm{DE})$ & 80 & 2 & 2 & 3 & 2 & 3 \\
\hline $7(\mathrm{DF})$ & 100 & 2 & 2 & 3 & 2 & 3 \\
\hline $8(\mathrm{EF})$ & 200 & 2 & 2 & 3 & 3 & 2 \\
\hline
\end{tabular}

- Koefisien Hazen-Williams $\left(\mathrm{C}_{\mathrm{HW}}\right)=142$ dan koefisien Manning $(\mathrm{n})=0,011$.

- Debit air yang masuk berasal dari 2 titik, yaitu: titik A sebesar 30 lt/det dan titik F sebesar $10 \mathrm{lt} / \mathrm{det}$.

- Debit air yang keluar dari 2 titik, yaitu: titik B sebesar 15 lt/det dan titik C sebesar $25 \mathrm{lt} / \mathrm{det}$.

- Kehilangan energi yang diperhitungkan hanya kehilangan energi primer, sedangkan kehilangan energi sekunder tidak diperhitungkan.

\section{PENGOLAHAN DATA}

Data-data tersebut di atas dapat dihitung menggunakan Metoda Hardy-Cross dengan rumus Hazel-Williams dan rumus Manning. Dalam kasus-kasus di atas pemilihan debit terkaan awal $\left(\mathrm{Q}_{0}\right)$ dipilih dengan nilai yang selalu sama untuk semua kasus, yaitu sebagai berikut:

- Titik A: Pipa 1 (AB) keluar 20 lt/det, pipa 5 (AE) keluar 10 lt/det dan debit masuk $30 \mathrm{lt} / \mathrm{det}$.

- Titik B: Pipa 1 (AB) masuk 20 lt/det, pipa 2 (BC) keluar 15 lt/det, pipa 4 (BD) masuk 10 lt/det dan debit keluar 15 lt/det.

- Titik C: Pipa 2 (BC) masuk 15 lt/det, pipa 3 (CD) masuk 10 lt/det dan debit keluar $25 \mathrm{lt} / \mathrm{det}$.

- Ttitik D: Pipa 3 (CD) keluar 10 lt/det, pipa 4 (BD) keluar 10 lt/det, pipa 6 (DE) masuk 15 lt/det dan pipa 7 (DF) masuk 5 lt/det. 
- $\quad$ Titik E: Pipa 5 (AE) masuk 10 lt/det, pipa 6 (DE) keluar 15 lt/det dan pipa 8 (EF) masuk 5 lt/det.

- Titik F: Pipa 7 (DF) keluar 5 lt/det, pipa 8 (EF) keluar 5 lt/det dan debit masuk 10 $1 \mathrm{t} /$ det.

Metoda Hardy-Cross yang dibantu oleh program komputer Microsoft Excel akan terus mengulang (interasi) debit dengan koreksi debit pada masing-masing pendekatan sehingga mendapatkan debit-debit yang merupakan debit optimum dari tiap-tiap ruas jaringan pipa. Pada tabel-tabel di halaman berikut dapat dilihat hasil Metoda Hardy-Cross yang menghasilkan debit optimum pada masing-masing kasus.

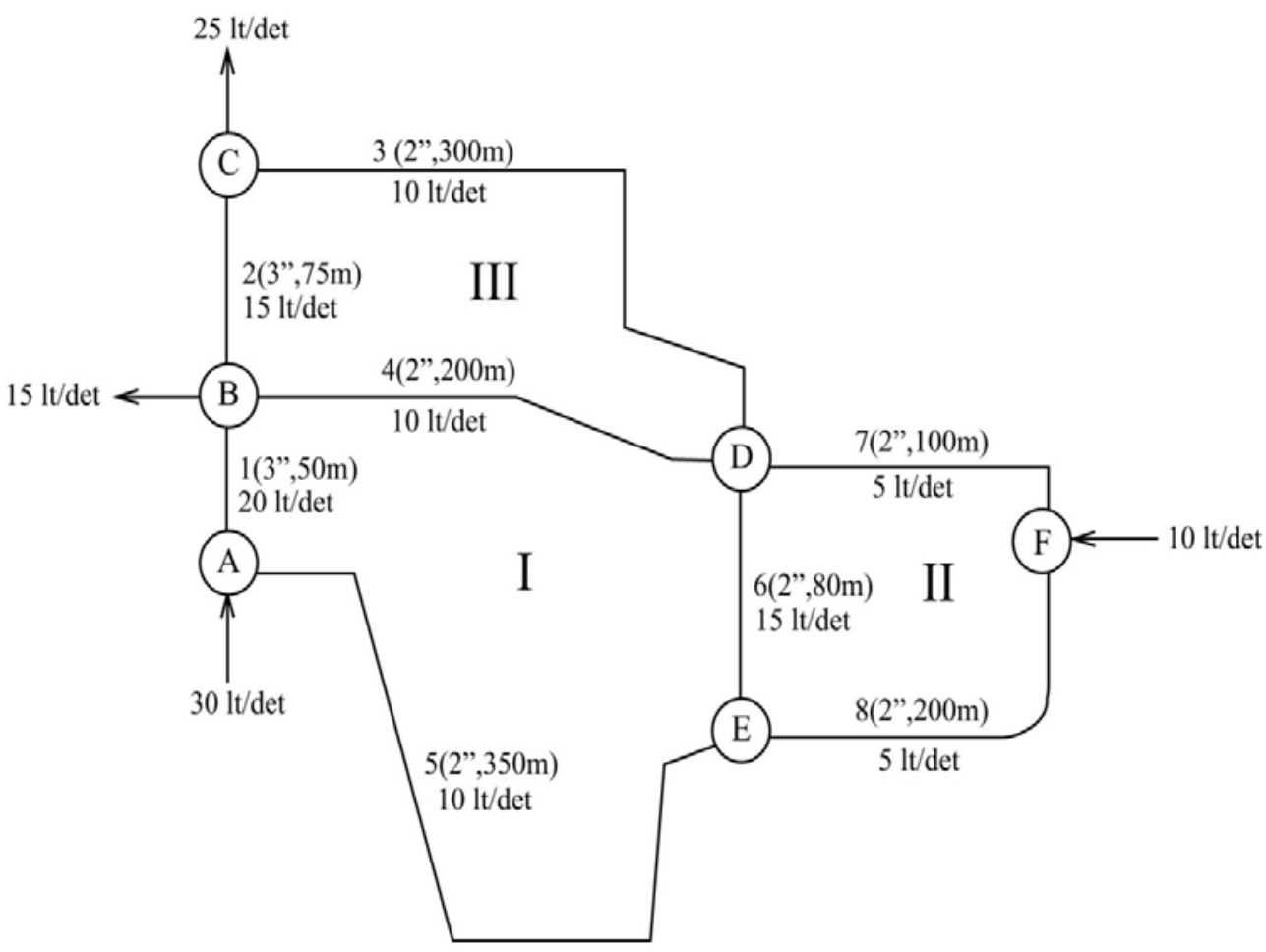

Gambar 2. Kasus 1.

Perhitungan Debit Pada Sistem Jaringan Pipa dengan Metode Hardy-Cross Menggunakan Rumus Hazen-Williams dan Rumus 
Tabel 2. Syarat Kontinuitas.

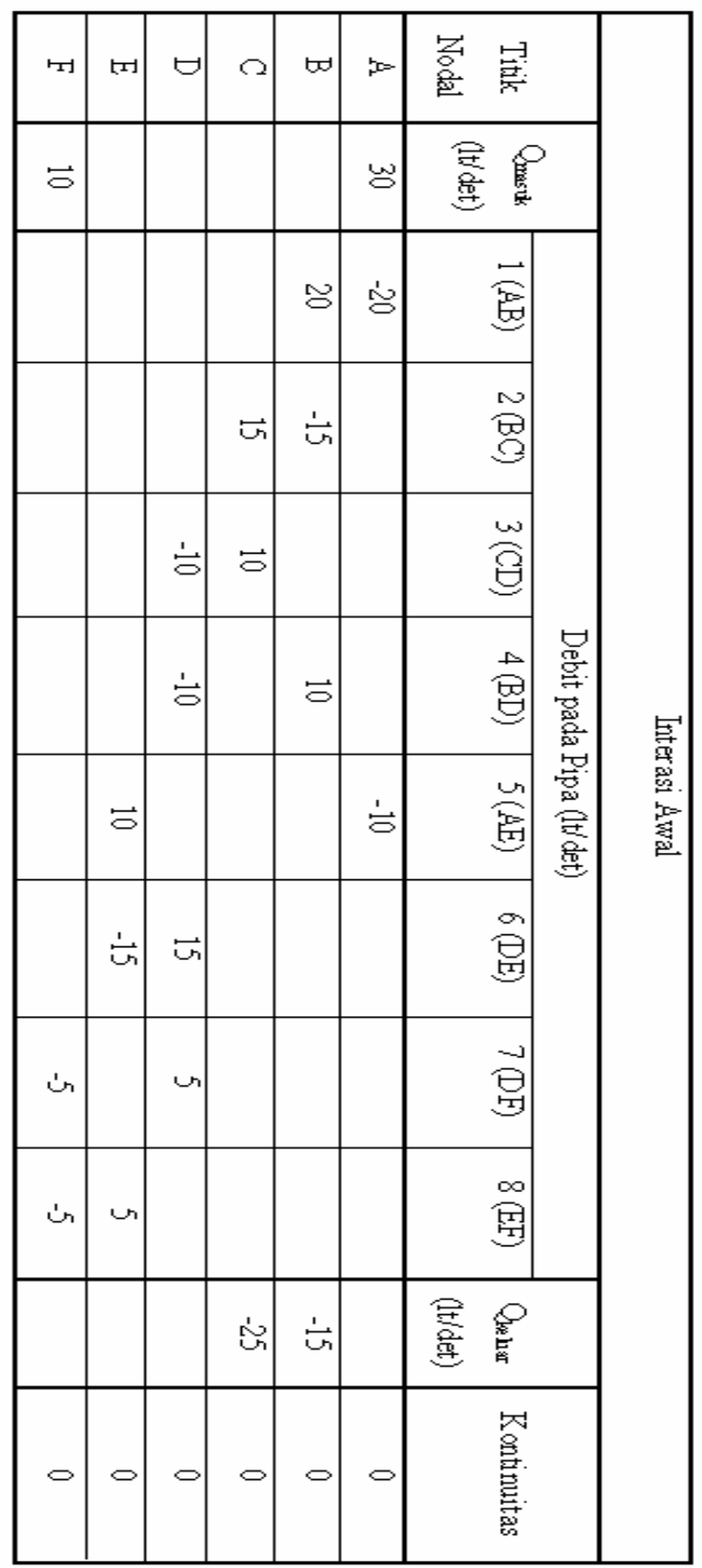




\section{PERHITUNGAN KONSTANTA HAMBATAN HARDY-CROSS (k)}

Rumus Hasen-Williams:

$$
k=\frac{10,68 L}{C_{H W}^{1,852} D^{4,87}}
$$

Kasus 1:

Contoh Pipa $1(\mathrm{AB})$

$\mathrm{C}_{\mathrm{HW}}=142$

$\mathrm{L} \quad=50 \mathrm{~m}$

$\mathrm{D} \quad=3$ in

$k=\frac{10,68 \times 50}{142^{1,852} \times\left(3 \times \frac{2,54}{100}\right)^{4,87}}=15359,69$

Nilai k untuk pipa-pipa lainnya dapat dihitung degan cara yang sama dengan diatas.

\section{Rumus Manning}

$$
k=\frac{10,29 n^{\prime 2} L}{D^{16 / 3}}
$$

Kasus 1:

Contoh Pipa $1(\mathrm{AB})$

n' $\quad=0,011$

$\mathrm{L} \quad=50 \mathrm{~m}$

$\mathrm{D} \quad=3$ in

$$
k=\frac{10,29 \times 0,011^{2} \times 50}{\left(3 \times \frac{2,54}{100}-\right)^{16 / 3}}=57158,07
$$

Nilai k untuk pipa-pipa lainnya dapat dihitung degan cara yang sama dengan diatas

\section{PERHITUNGAN DEBIT PADA MASING-MASING PIPA DENGAN METODA HARDY-CROSS}

Rumus umum metode Hardy-Cross:

$$
\Delta Q=\frac{\sum k Q_{0}^{n}}{\sum\left|n k Q_{0}^{n-1}\right|} \leq 5 \% Q_{\text {terkecil }}
$$

Perhitungan Debit Pada Sistem Jaringan Pipa dengan Metode Hardy-Cross Menggunakan Rumus Hazen-Williams dan Rumus 
Rumus Hasen-Williams:

$$
\begin{aligned}
& \mathrm{n}=1,852 \\
& \Delta Q=\frac{\sum k Q_{0}^{1,852}}{\sum\left|1,852 k Q_{0}^{0,852}\right|} \leq 5 \% Q_{\text {terkecil }}
\end{aligned}
$$

Contoh perhitungan kasus 1 :

Iterasi I

Tabel 3.

\begin{tabular}{|c|c|c|c|c|c|}
\hline \multicolumn{6}{|c|}{ Jaringan I } \\
\hline Pipa & Arah & $\mathrm{k}$ & $\mathrm{Q}_{0}$ & $\mathrm{~K} \mathrm{Q}_{0}{ }^{1,852}$ & $\mid 1,852 \mathrm{k} \mathrm{Q}_{0}{ }^{0,852}$ \\
\hline $1(\mathrm{AB})$ & + & 15359,69 & 20,00 & 3943574,82 & 365175,03 \\
\hline $4(\mathrm{BD})$ & - & 442595,46 & 10,00 & $-31477987,29$ & 5829723,25 \\
\hline $5(\mathrm{AE})$ & - & 774542,06 & 10,00 & $-55086477,76$ & 10202015,68 \\
\hline $6(\mathrm{DE})$ & - & 177038,18 & 15,00 & $-26680131,07$ & 3294106,85 \\
\hline \multicolumn{7}{|c|}{$\Sigma$} & $-109301021,31$ & 19691020,81 \\
\hline
\end{tabular}

$\Delta Q=\frac{-109301021,31}{19691020,81}=-5,55 \mathrm{lt} / \mathrm{det} \leq 5 \% \times 5=0,25 \mathrm{lt} / \mathrm{det} \ldots$.tidakOk!

Tabel 4.

\begin{tabular}{|c|c|c|c|c|c|}
\hline \multicolumn{5}{|c|}{ Jaringan II } \\
\hline Pipa & Arah & $\mathrm{k}$ & $\mathrm{Q}_{0}$ & $\mathrm{~K} \mathrm{Q}_{0}{ }^{1,852}$ & $\left|1,852 \mathrm{k} \mathrm{Q}_{0}{ }^{0,852}\right|$ \\
\hline $6(\mathrm{DE})$ & + & 177038,18 & 15,00 & 26680131,07 & 3294106,85 \\
\hline $7(\mathrm{DF})$ & - & 221297,73 & 5,00 & $-4359828,52$ & 1614880,48 \\
\hline $8(\mathrm{EF})$ & + & 442595,46 & 5,00 & 8719657,04 & 3229760,97 \\
\hline \multicolumn{7}{|c|}{$\Sigma$} & 31039959,59 & 8138748,30 \\
\hline
\end{tabular}

$\Delta Q=\frac{31039959,59}{8138748,30}=3,81$ lt $/$ det $\leq 5 \% \times 5=0,25$ lt $/$ det ...tidakOk!

Tabel 5.

\begin{tabular}{|c|c|c|c|c|c|}
\hline \multicolumn{6}{|c|}{ Jaringan III } \\
\hline Pipa & Arah & $\mathrm{k}$ & $\mathrm{Q}_{0}$ & $\mathrm{~K} \mathrm{Q}_{0}{ }^{1,852}$ & $\left|1,852 \mathrm{k} \mathrm{Q}_{0}{ }^{0,852}\right|$ \\
\hline $2(\mathrm{BC})$ & + & 23039,54 & 15,00 & 3472120,62 & 428691,16 \\
\hline $3(\mathrm{CD})$ & - & 663893,19 & 10,00 & $-47216980,94$ & 8744584,87 \\
\hline \multicolumn{7}{|c|}{$\Sigma$} & $-12266873,03$ & 15002999,28 \\
\hline
\end{tabular}


$\Delta Q=\frac{-12266873,03}{15002999,28}=-0,82$ lt $/$ det $\leq 5 \% x 5=0,25 l t /$ det $\ldots$ tidakOk!

\section{Koreksi Debit Iterasi I:}

\section{Jaring I:}

Pipa $1(\mathrm{AB})=+20+5,55=+25,55 \mathrm{lt} / \mathrm{det}$

Pipa $4(B D)=-10+5,55=--4,45-1 \mathrm{l} / \mathrm{det}$

Pipa $5(\mathrm{AE})=-10+5,55=-4,55 \mathrm{lt} / \mathrm{det}$

Pipa $6(\mathrm{DE})=-15+5,55=--9,45-1 \mathrm{t} / \mathrm{det}$

\section{Jaring II:}

Pipa $6(\mathrm{DE})=+9,45-3,81=+5,64 \mathrm{lt} / \mathrm{det}$

Pipa $7(\mathrm{DF})=-5--3,81=-8,81 \mathrm{lt} / \mathrm{det}$

Pipa $8(E F)=+5--3,81=+1,19 \mathrm{lt} / \mathrm{det}$

\section{Jaring III:}

Pipa $2(\mathrm{BC})=+15+0,82=+15,82 \mathrm{lt} / \mathrm{det}$

Pipa $3(C D)=-10+0,82=-9,18$ lt $/$ det

Pipa $4(B D)=+4,45+0,82=+5,27$ lt $/$ det

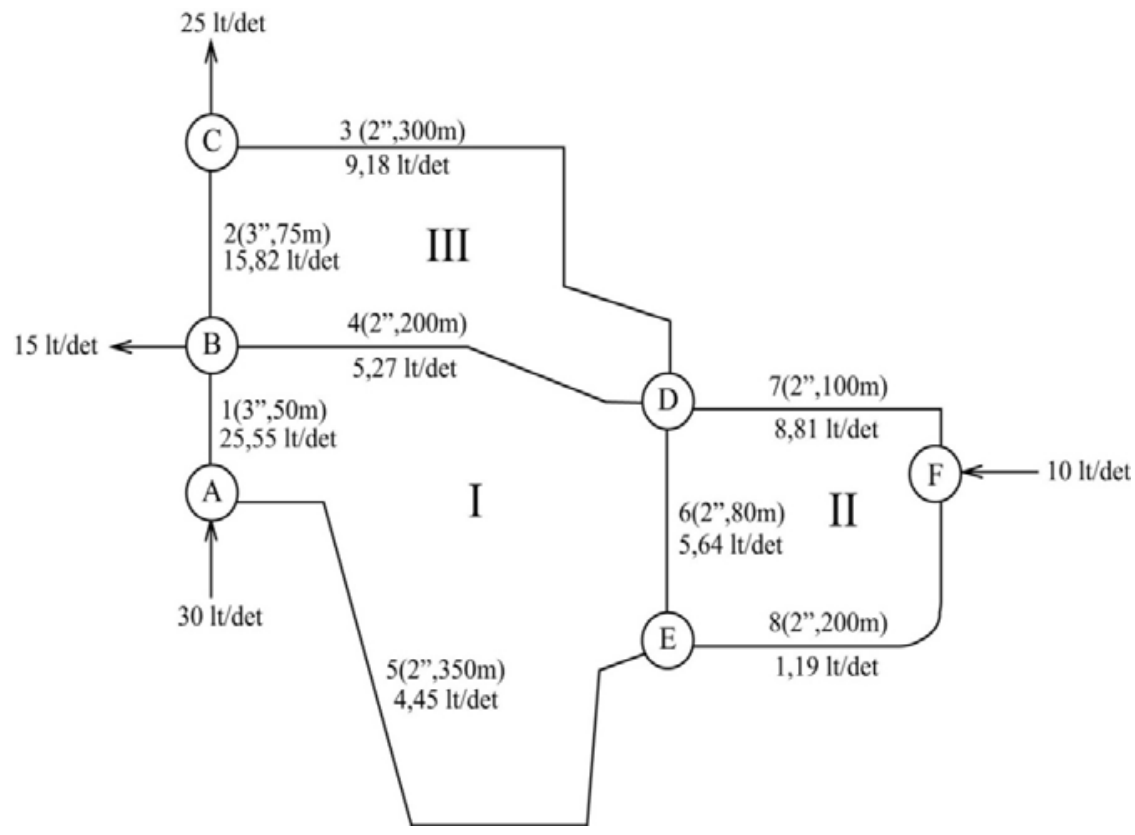

Gambar 3.

Perhitungan Debit Pada Sistem Jaringan Pipa dengan Metode Hardy-Cross Menggunakan Rumus Hazen-Williams dan Rumus 
Tabel 6. syarat Kontinuitas.

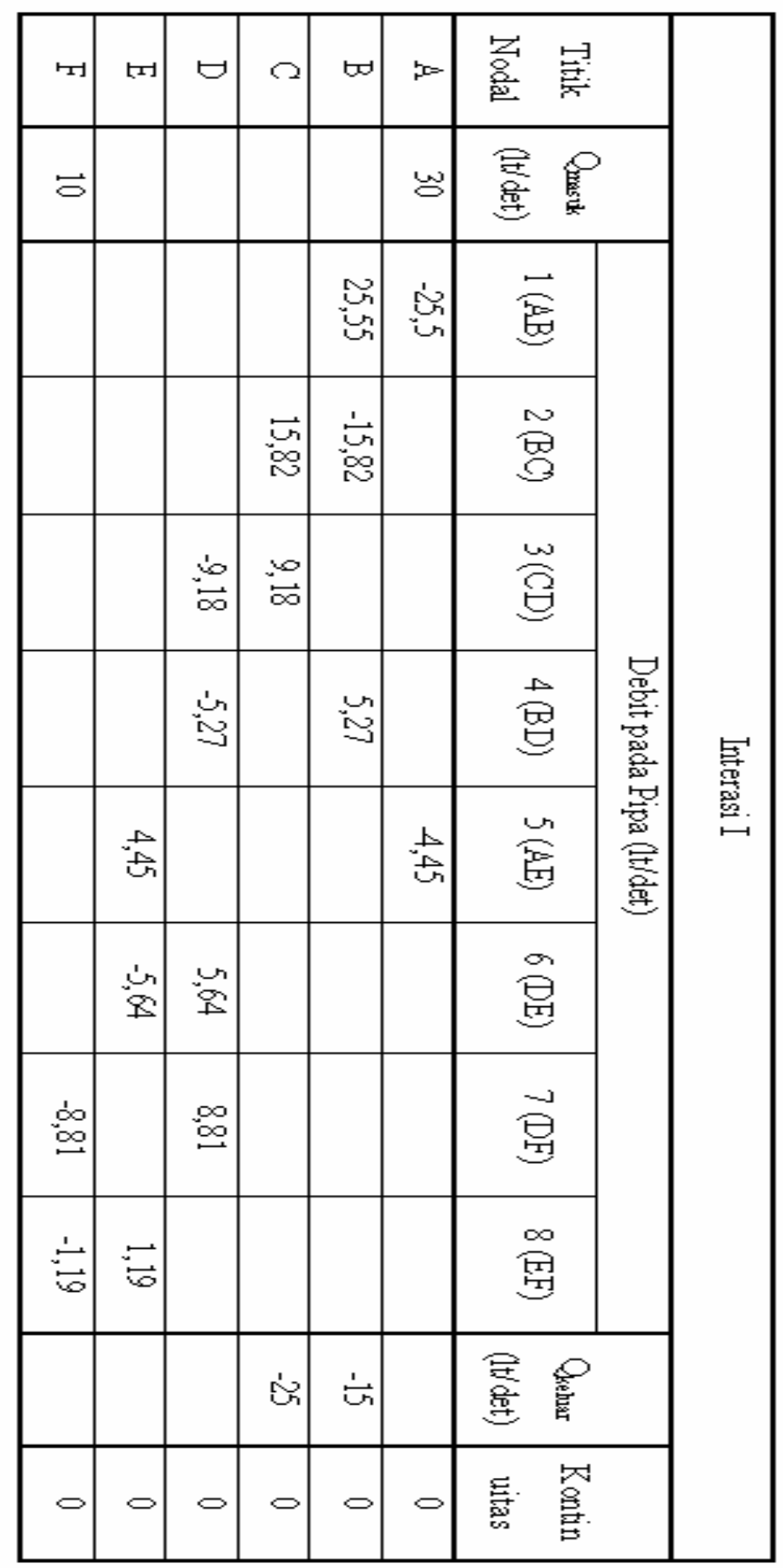


Lanjutkan iterasi II, III, IV dan seterusnya sampai hasil perhitungan $\Delta \mathrm{Q} \leq 5 \%$ terhadap debit yang terkecil pada masing-masing jaring.

Hasil akhir dengan rumus Hazen-William untuk kasus 1, sebagai berikut:

\section{Jaring I:}

Pipa $1(\mathrm{AB})=+30,47 \mathrm{lt} / \mathrm{det}$

Pipa $4(\mathrm{BD})=-4,52 \mathrm{lt} / \mathrm{det}$

Pipa $5(\mathrm{AE})=+0,47 \mathrm{lt} / \mathrm{det}$

Pipa $6(\mathrm{DE})=-3,26 \mathrm{lt} / \mathrm{det}$

\section{Jaring II:}

Pipa $6(\mathrm{DE})=+3,26$ lt $/ \mathrm{det}$

Pipa $7(\mathrm{DE})=-6,27 \mathrm{lt} / \mathrm{det}$

Pipa $8(E F)=+3,731 t /$ det

\section{Jaring III:}

Pipa $2(\mathrm{BC})=+19,99 \mathrm{lt} / \mathrm{det}$

Pipa $3(\mathrm{CD})=-5,01 \mathrm{lt} / \mathrm{det}$

Pipa $4(\mathrm{BD})=+4,52 \mathrm{lt} / \mathrm{det}$

Untuk kasus 2, 3, 4 dan 5 dapat dilakukan dengan cara yang sama dengan kasus 1 .

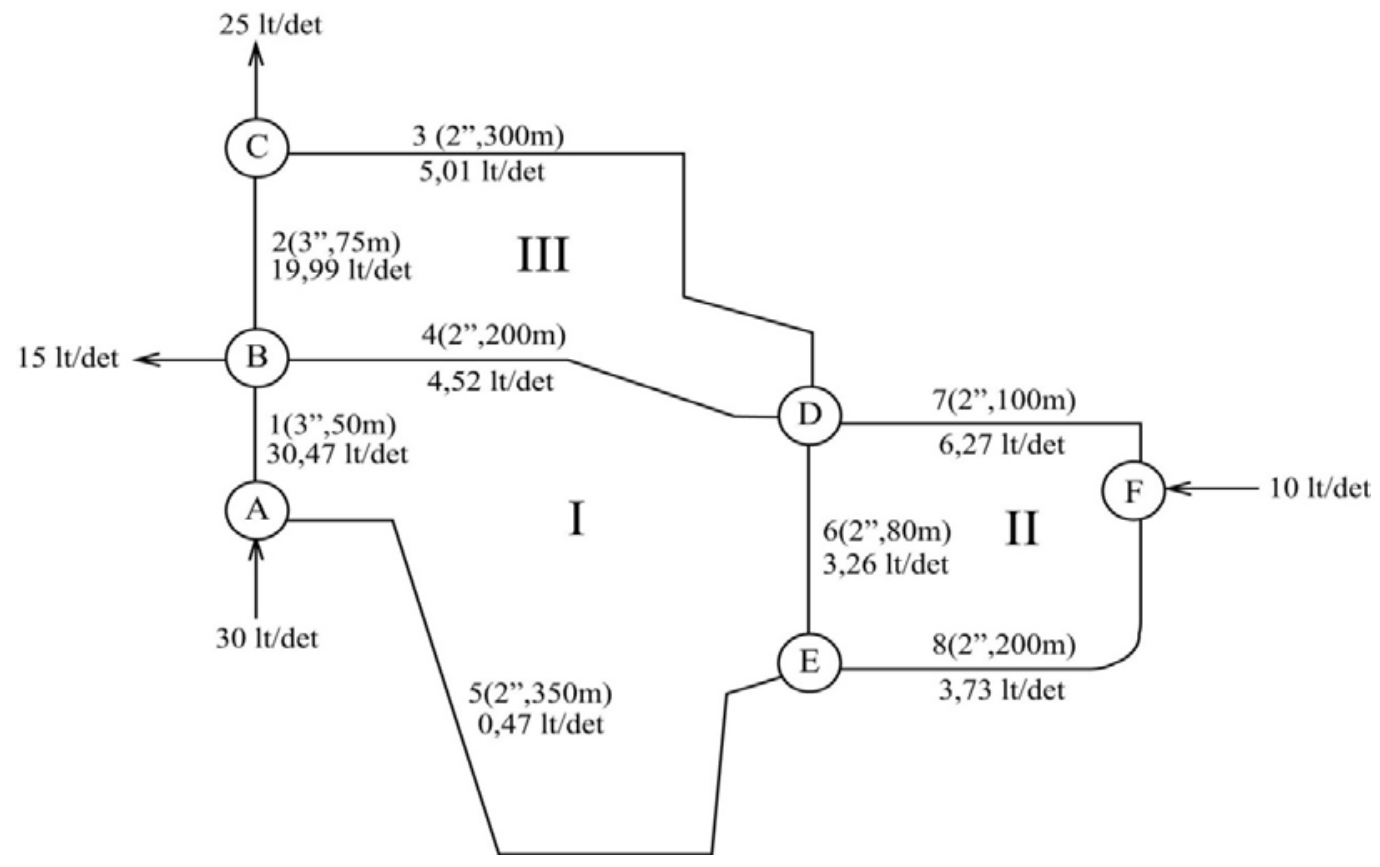

Gambar 4.

Perhitungan Debit Pada Sistem Jaringan Pipa dengan Metode Hardy-Cross Menggunakan Rumus Hazen-Williams dan Rumus 
Tabel 7. Syarat Kontinuitas.

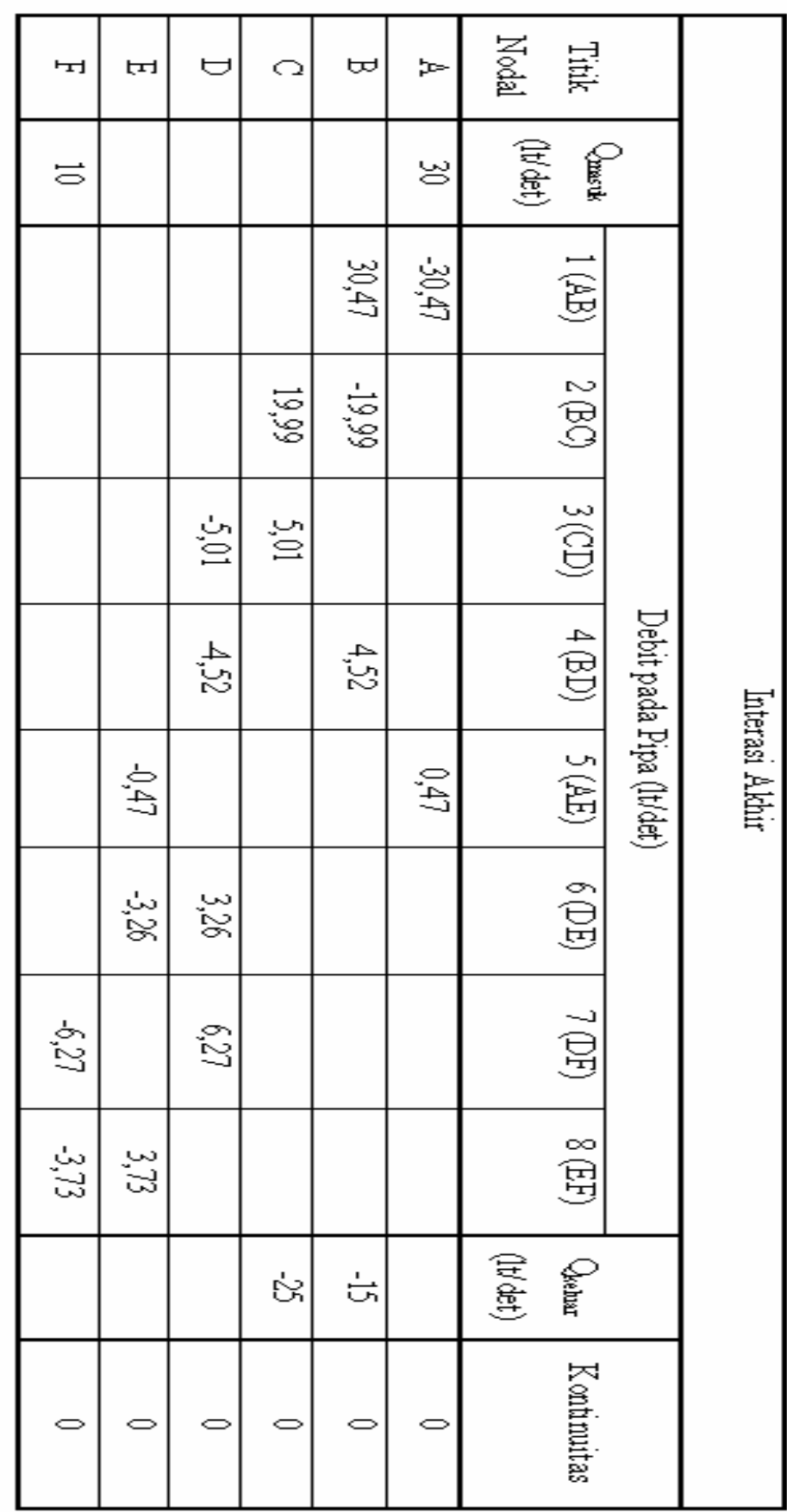




\section{Rumus Manning}

$$
\begin{aligned}
& \mathrm{n}=2 \\
& \Delta Q=\frac{\sum k Q_{0}^{2}}{\sum\left|2 k Q_{0}\right|} \leq 5 \% Q_{\text {terkecil }}
\end{aligned}
$$

Contoh perhitungan kasus 1

Iterasi I

Tabel 8.

\begin{tabular}{|c|c|c|c|c|c|}
\hline \multicolumn{7}{|c|}{ Jaringan I } \\
\hline Pipa & Arah & $\mathrm{k}$ & $\mathrm{Q}_{0}$ & $\mathrm{~K} \mathrm{Q}_{0}{ }^{2}$ & $\left|2 \mathrm{k} \mathrm{Q}_{0}\right|$ \\
\hline $1(\mathrm{AB})$ & + & 57158,07 & 20,00 & 22863228,68 & 2286322,87 \\
\hline $4(\mathrm{BD})$ & - & 1987425,88 & 10,00 & $-198742588,48$ & 39748517,70 \\
\hline $5(\mathrm{AE})$ & - & 3477995,30 & 10,00 & $-347799529,84$ & 69559905,97 \\
\hline $6(\mathrm{DE})$ & - & 794970,35 & 15,00 & $-178868329,63$ & 23849110,62 \\
\hline \multicolumn{7}{|c|}{$\Sigma$} & $-702547219,27$ & 135443857,15 \\
\hline
\end{tabular}

$$
\Delta Q=\frac{-702547219,27}{135443857,15}=-5,19 l t / \operatorname{det} \leq 5 \% \times 5=0,25 l t / \operatorname{det} \ldots \text { tidakOk! }
$$

Tabel 9.

\begin{tabular}{|c|c|c|c|c|c|}
\hline \multicolumn{6}{|c|}{ Jaringan II } \\
\hline Pipa & Arah & $\mathrm{k}$ & $\mathrm{Q}_{0}$ & $\mathrm{~K} \mathrm{Q}_{0}{ }^{2}$ & $\left|2 \mathrm{k} \mathrm{Q}_{0}\right|$ \\
\hline $6(\mathrm{DE})$ & + & 794970,35 & 15,00 & 178868329,63 & 23849110,62 \\
\hline $7(\mathrm{DF})$ & - & 993712,94 & 5,00 & $-24842823,56$ & 9937129,42 \\
\hline $8(\mathrm{EF})$ & + & 1987425,88 & 5,00 & 49685647,12 & 19874258,85 \\
\hline \multicolumn{7}{|c|}{$\Sigma$} & 203711153,19 & 53660498,89 \\
\hline
\end{tabular}

$\Delta Q=\frac{203711153,19}{53660498,85}=3,80$ lt $/$ det $\leq 5 \% \times 5=0,25$ lt $/$ det $\ldots$.tidakOk!

Tabel 10.

\begin{tabular}{|c|c|c|c|c|c|}
\hline \multicolumn{6}{|c|}{ Jaringan III } \\
\hline Pipa & Arah & $\mathrm{k}$ & $\mathrm{Q}_{0}$ & $\mathrm{~K} \mathrm{Q}_{0}{ }^{2}$ & $\left|2 \mathrm{k} \mathrm{Q}_{0}\right|$ \\
\hline $2(\mathrm{BC})$ & + & 85737,11 & 15,00 & 19290849,20 & 2572113,23 \\
\hline $3(\mathrm{CD})$ & - & 2981138,83 & 10,00 & $-298113882,72$ & 59622776,54 \\
\hline $4(\mathrm{BD})$ & + & 1987425,88 & 10,00 & 198742588,48 & 39748517,70 \\
\hline \multicolumn{7}{|c|}{$\Sigma$} & $-80080445,04$ & 101943407,47 \\
\hline
\end{tabular}

Perhitungan Debit Pada Sistem Jaringan Pipa dengan Metode Hardy-Cross Menggunakan Rumus Hazen-Williams dan Rumus 
$\Delta Q=\frac{-80080445,04}{101943407,47}=-0,79 l t / \operatorname{det} \leq 5 \% \times 5=0,25$ lt $/$ det $\ldots$ tidakOk!

\section{Koreksi Debit Iterasi I:}

\section{Jaring I:}

Pipa $1(\mathrm{AB})=+20+5,19=+25,19 \mathrm{lt} / \mathrm{det}$

Pipa $4(B D)=-10+5,19=--4,81-1 t / d e t$

Pipa $5(\mathrm{AE})=-10+5,19=-4,81 \mathrm{lt} / \mathrm{det}$

Pipa $6(\mathrm{DE})=-15+5,19=-9,81 \mathrm{lt} / \mathrm{det}$

\section{Jaring II:}

Pipa $6(\mathrm{DE})=+9,81-3,80=+6,01 \mathrm{lt} / \mathrm{det}$

Pipa $7(D F)=-5-3,80=-8,80 \mathrm{lt} / \mathrm{det}$

Pipa $8(\mathrm{EF})=+5-3,80=+1,20 \mathrm{lt} / \mathrm{det}$

\section{Jaring III:}

Pipa $2(\mathrm{BC})=+15+0,79=+15,79 \mathrm{lt} / \mathrm{det}$

Pipa $3(C D)=-10+0,79=-9,21 \mathrm{lt} / \mathrm{det}$

Pipa $4(\mathrm{BD})=+4,81+0,79=+5,60 \mathrm{lt} / \mathrm{det}$

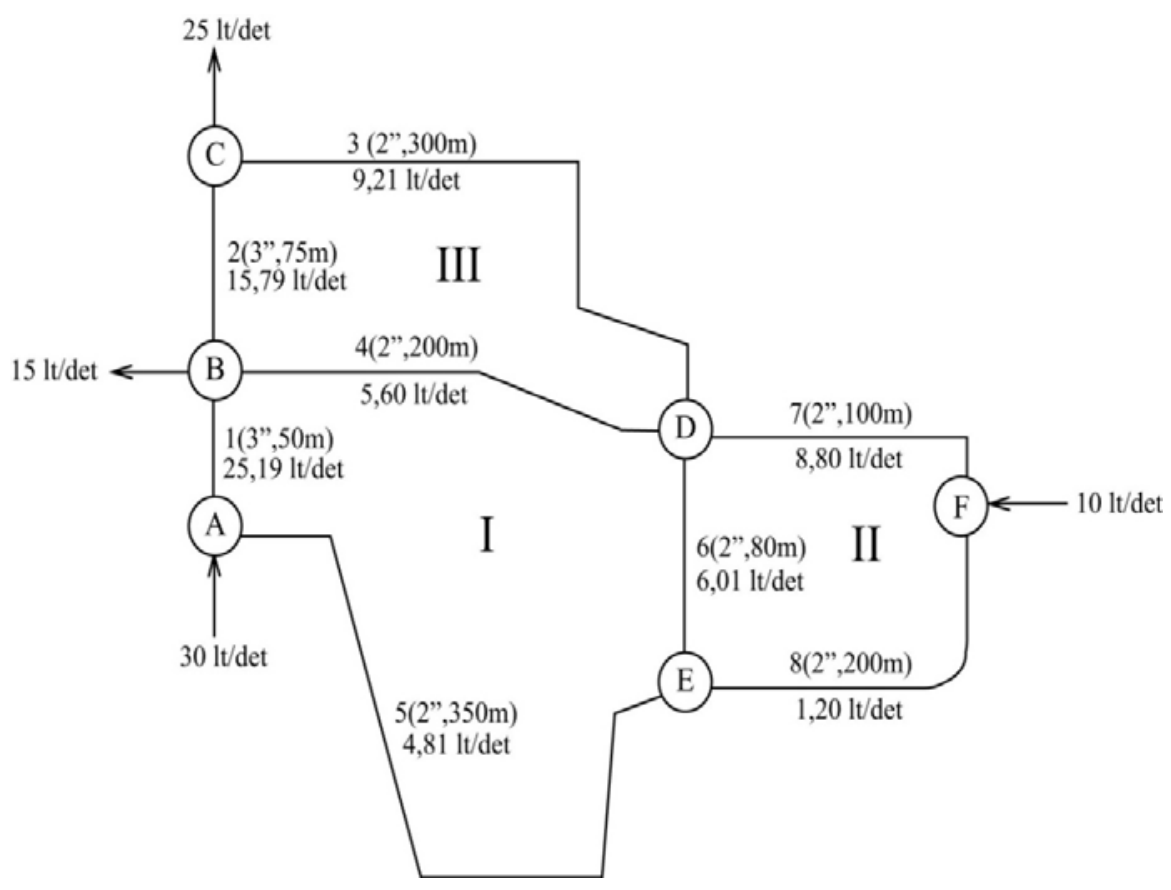

Gambar 5. 
Tabel 11. Syarat Kontinuitas.

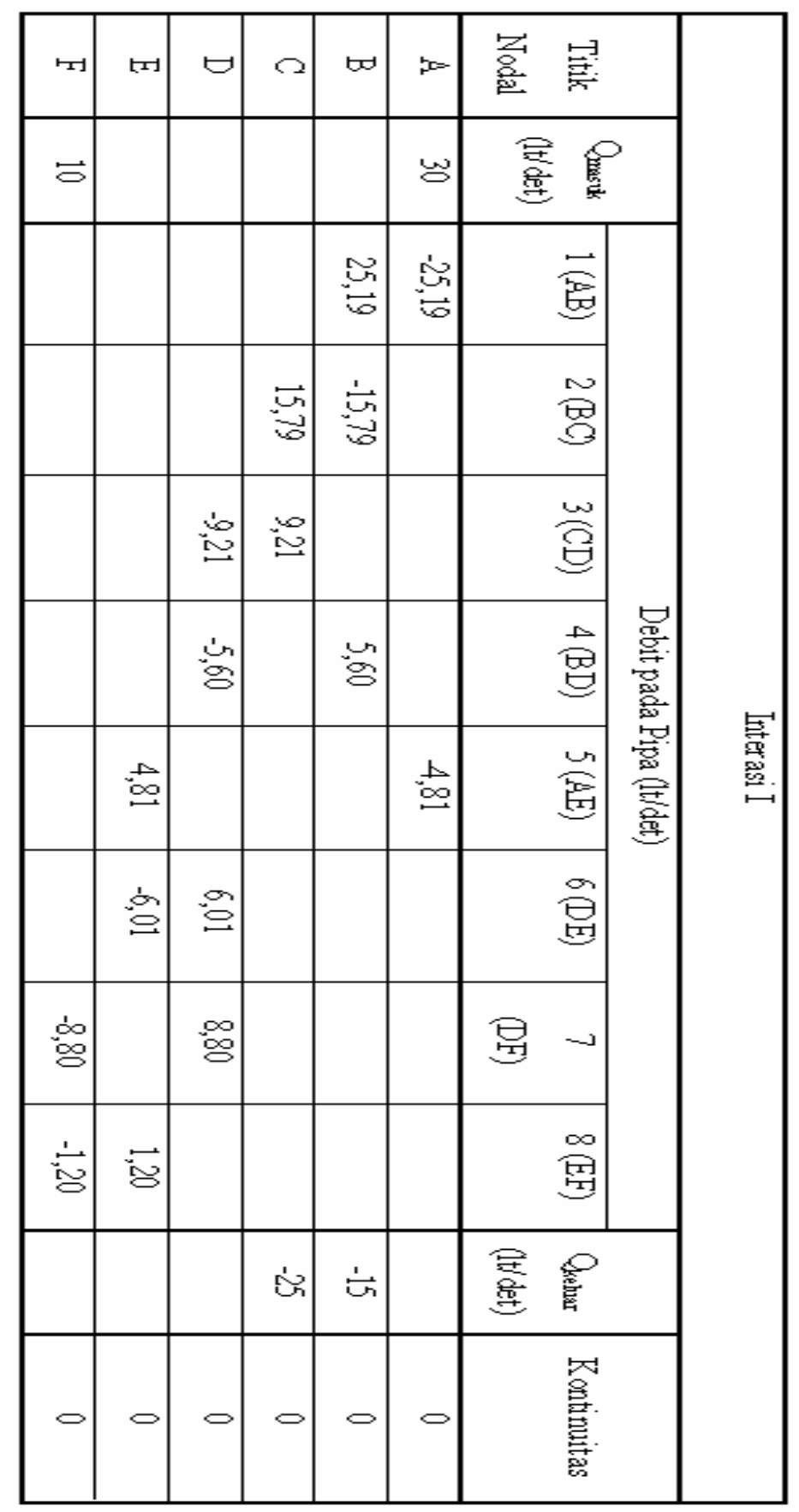


Lanjutkan iterasi II, III, IV dan seterusnya sampai hasil perhitungan $\Delta \mathrm{Q} \leq 5 \%$ terhadap debit yang terkecil pada masing-masing jaring.

Hasil akhir dengan rumus Manning untuk kasus 1, sebagai berikut:

\section{Jaring I:}

Pipa $1(\mathrm{AB})=+30,28 \mathrm{lt} / \mathrm{det}$

Pipa $4(B D)=-4,64$ lt $/$ det

Pipa $5(\mathrm{AE})=+0,28 \mathrm{lt} / \mathrm{det}$

Pipa $6(\mathrm{DE})=-3,51 \mathrm{lt} / \mathrm{det}$

\section{Jaring II:}

Pipa $6(\mathrm{DE})=+3,51 \mathrm{lt} / \mathrm{det}$

Pipa $7(\mathrm{DE})=-6,21 \mathrm{lt} / \mathrm{det}$

Pipa $8(\mathrm{EF})=+3,79 \mathrm{lt} / \mathrm{det}$

\section{Jaring III:}

Pipa $2(\mathrm{BC})=+19,92 \mathrm{lt} / \mathrm{det}$

Pipa $3(\mathrm{CD})=-5,08 \mathrm{lt} / \mathrm{det}$

Pipa $4(\mathrm{BD})=+4,64 \mathrm{lt} / \mathrm{det}$

Untuk kasus 2, 3, 4 dan 5 dapat dilakukan dengan cara yang sama dengan kasus 1.

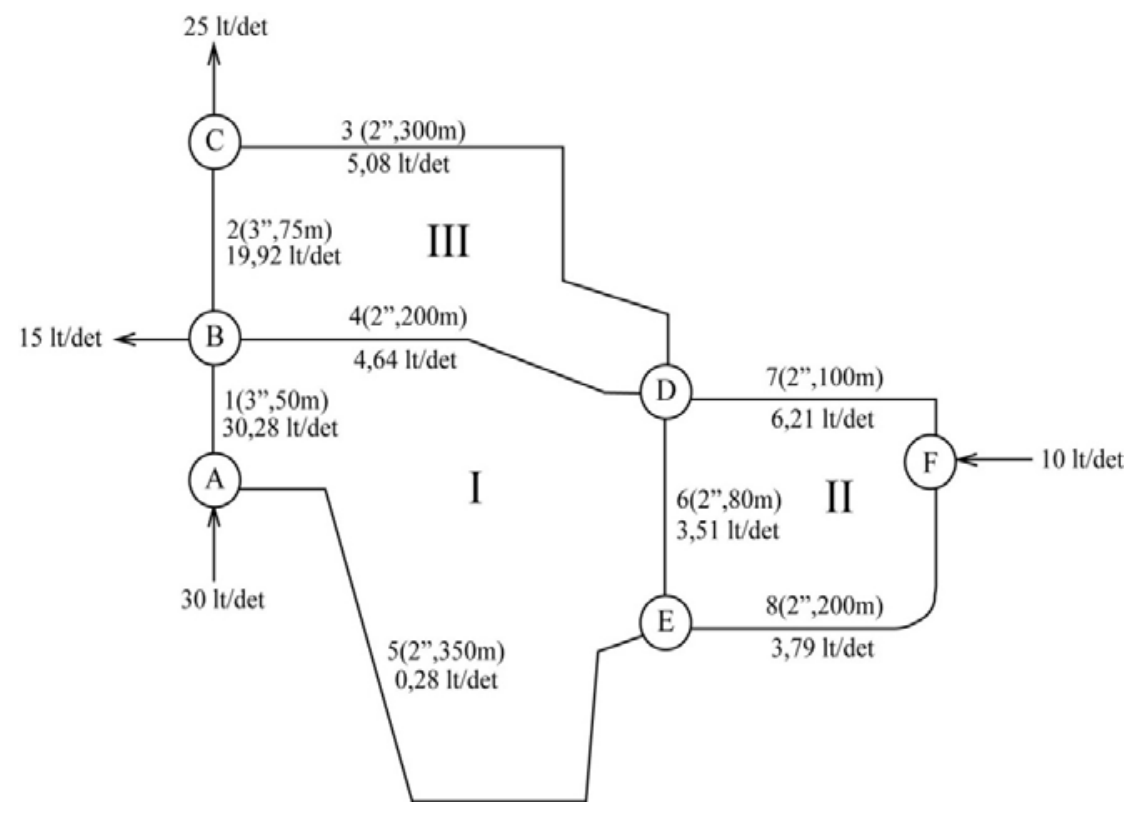

\section{Gambar 6}


Tabel 12. Syarat Kontinuitas.

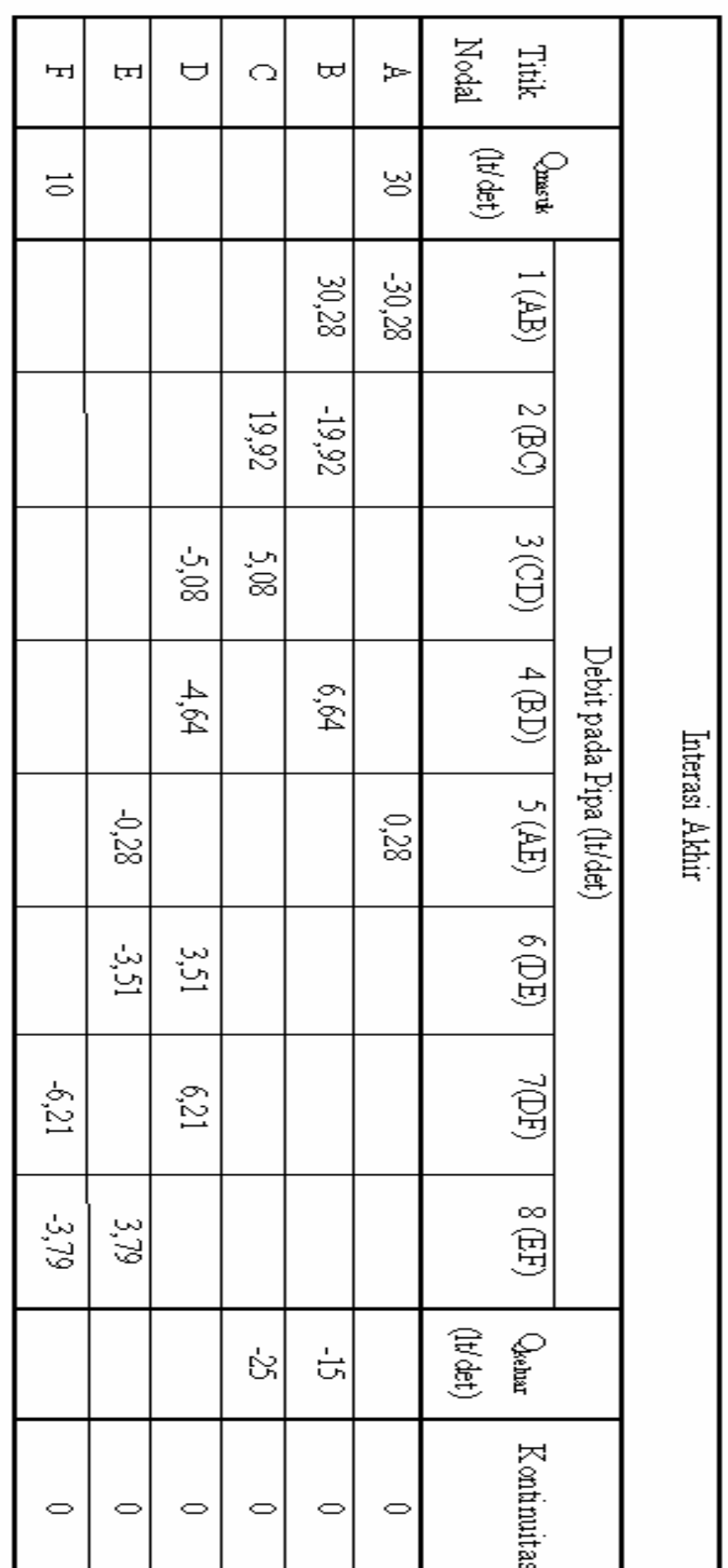


Manning pada Tiap-tiap Kasus.

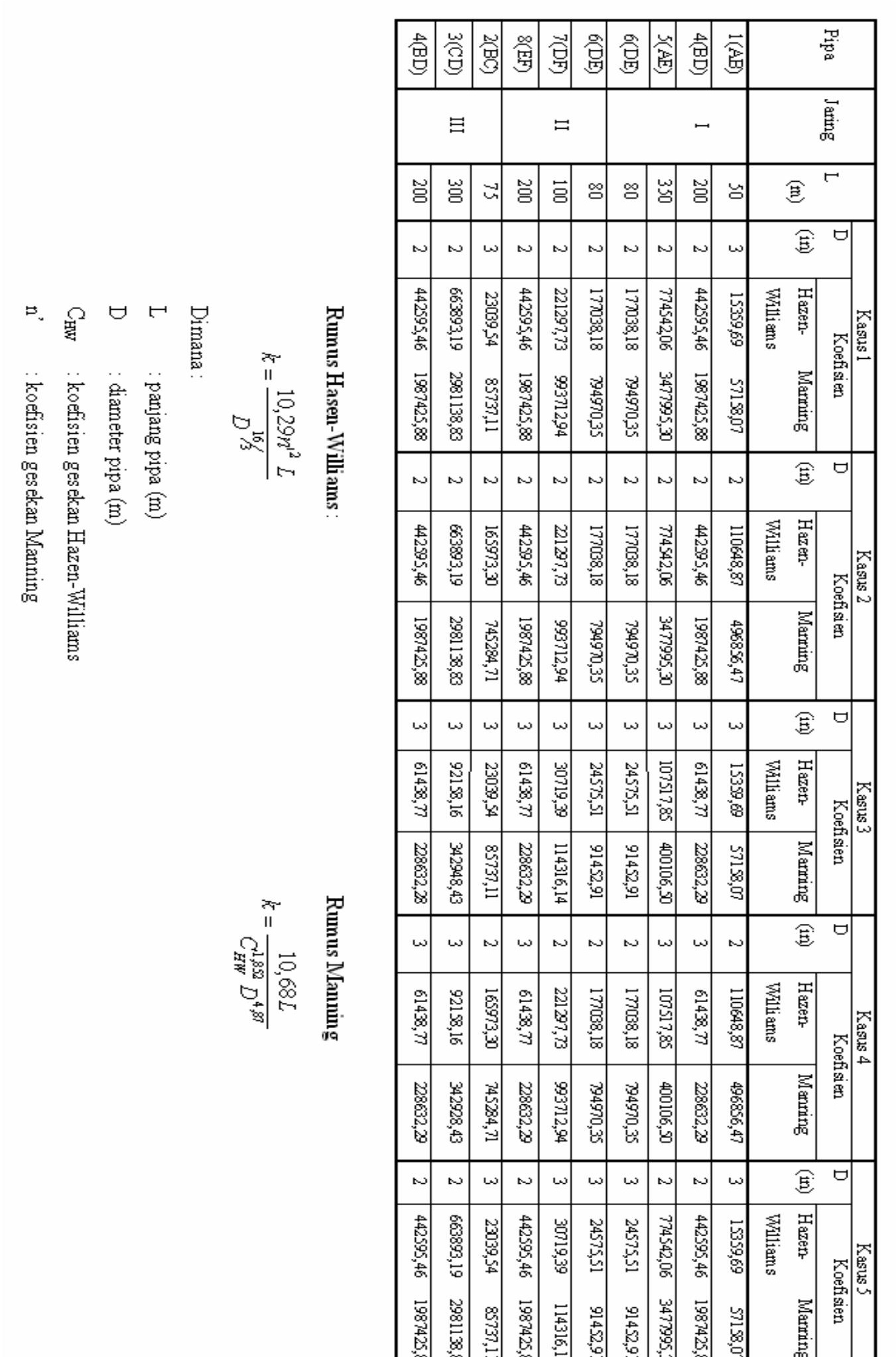




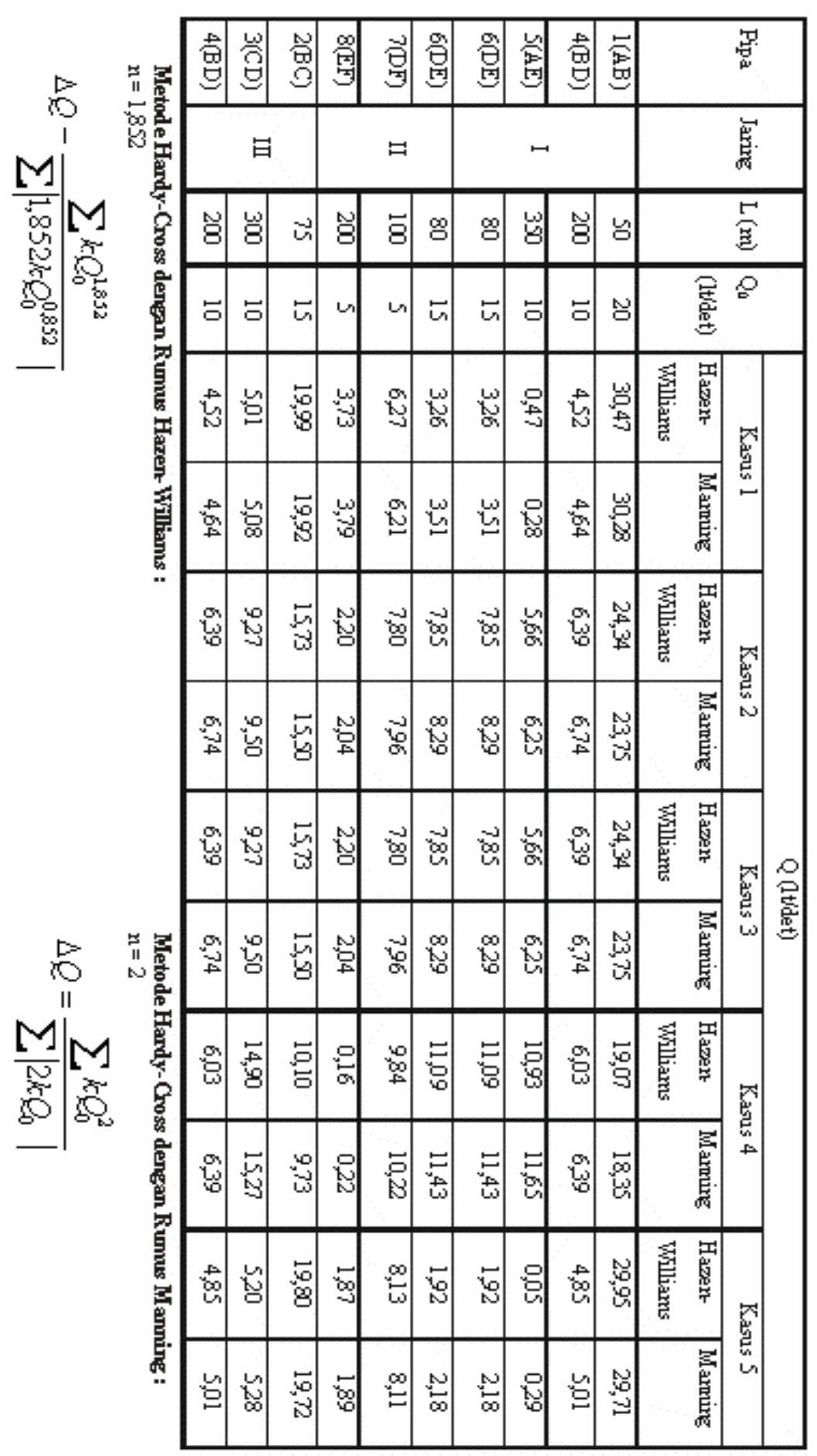




\section{KESIMPULAN}

Dari hasil analisis perhitungan debit pada sebagian jaringan pipa PDAM di kota Padalarang Bandung, menggunakan Metoda Hardy-Cross dengan rumus Hazen-William dan rumus Manning, dapat disimpulkan :

a. Nilai konstanta hambatan pipa (k) pada Metoda Hardy-Cross berhubungan langsung dalam penentuan debit pada suatu jaringan pipa, seperti terlihat pada persamaan berikut ini :

$$
\begin{aligned}
& \mathrm{Q}_{2}=\mathrm{Q}_{1} \pm \Delta \mathrm{Q} \\
& Q_{2}=Q_{1} \pm \frac{\sum k Q_{0}^{n}}{\sum\left|n k Q_{0}^{n-1}\right|}
\end{aligned}
$$

b. Hasil debit yang didapat dengan Metoda Hardy-Cross menurut rumus HazenWilliams.

\begin{tabular}{|c|c|c|c|c|c|c|c|c|c|c|c|c|}
\hline \multirow[t]{2}{*}{ Fipa } & \multirow{2}{*}{$\begin{array}{c}\mathrm{L} \\
(\mathrm{m})\end{array}$} & \multirow{2}{*}{$\begin{array}{c}Q_{0} \\
\text { (ltidet) }\end{array}$} & \multicolumn{10}{|c|}{$Q$ (1t/det) } \\
\hline & & & $\begin{array}{c}D \\
\text { (in) }\end{array}$ & $\begin{array}{c}\text { Kasus } \\
1\end{array}$ & $\begin{array}{c}D \\
\text { (in) }\end{array}$ & $\begin{array}{c}\text { Kavus } \\
2\end{array}$ & $\begin{array}{c}\mathrm{D} \\
\text { (in) }\end{array}$ & $\begin{array}{c}\text { Karus } \\
3\end{array}$ & $\begin{array}{c}\text { D } \\
\text { (in) }\end{array}$ & $\begin{array}{c}\text { Kasus } \\
4\end{array}$ & $\begin{array}{c}\mathrm{D} \\
\text { (in) }\end{array}$ & $\begin{array}{c}\text { Kagus } \\
5\end{array}$ \\
\hline $1(A B)$ & 50 & 20 & 3 & 30,47 & 2 & 24,34 & 3 & 24,34 & 2 & 19,07 & 3 & 29,95 \\
\hline $2(\mathrm{BC})$ & 75 & 15 & 3 & 19,99 & $\overline{2}$ & 15,73 & 3 & 15,73 & 2 & 10,10 & 3 & 19,80 \\
\hline $3(C D)$ & 300 & 10 & 2 & 5,01 & 2 & 9,27 & 3 & 9,27 & 3 & 14,90 & 2 & 5,20 \\
\hline $4(\mathrm{BD})$ & 200 & 10 & $\overline{2}$ & 4,52 & $\overline{2}$ & 6,39 & 3 & 6,39 & 3 & 6,03 & $\overline{2}$ & 4,85 \\
\hline $5(\mathrm{AE})$ & 350 & 10 & 2 & 0,47 & 2 & 5,66 & 3 & 5,66 & 3 & 10,93 & 2 & 0,05 \\
\hline $6(\mathrm{DE})$ & 80 & 15 & 2 & 326 & 2 & 7,85 & 3 & 7,85 & 2 & 11,09 & 3 & 192 \\
\hline 7 (DF) & 100 & 5 & 2 & 6,27 & 2 & 7,80 & 3 & 7,80 & 2 & 9,84 & 3 & 8,13 \\
\hline $8(\mathrm{EF})$ & 200 & 5 & 2 & 3,73 & 2 & 2,20 & 3 & 2,20 & 3 & 0,16 & 2 & 1,87 \\
\hline
\end{tabular}

Tabel 15.

Kesimpulan dari hasil diatas terlihat pada kasus 2 dan kasus 3, dengan menggunakan diameter pipa yang sama akan menghasilkan debit tetap (tidak berubah).

c. Hasil debit yang didapat dengan metode Hardy-Cross menurut rumus Manning

\begin{tabular}{|c|c|c|c|c|c|c|c|c|c|c|c|c|}
\hline \multirow[b]{2}{*}{ Fipa } & \multirow[b]{2}{*}{$\begin{array}{l}\mathrm{L} \\
\text { (m) }\end{array}$} & \multirow[b]{2}{*}{$\begin{array}{c}\mathrm{Q}_{\mathrm{d}} \\
\text { (lt/det) }\end{array}$} & \multicolumn{10}{|c|}{$Q$ (1t/det) } \\
\hline & & & $\begin{array}{c}D \\
\text { (in) }\end{array}$ & $\begin{array}{c}\text { Kasus } \\
1\end{array}$ & $\begin{array}{c}D \\
\text { (in) }\end{array}$ & $\begin{array}{c}\text { Kavis } \\
2\end{array}$ & $\begin{array}{c}D \\
\text { (in) }\end{array}$ & $\begin{array}{c}\text { Kasus } \\
3\end{array}$ & $\begin{array}{c}D \\
\text { (ini) }\end{array}$ & $\begin{array}{c}\text { Kavis } \\
4\end{array}$ & $\begin{array}{c}\mathrm{D} \\
\text { (in) }\end{array}$ & $\begin{array}{c}\text { Kaus } \\
5\end{array}$ \\
\hline $1(\mathrm{AB})$ & 50 & 20 & 3 & 30,28 & $\overline{2}$ & 23,75 & 3 & 23,75 & 2 & 18,35 & 3 & 29,71 \\
\hline$\overline{2(\mathrm{BC})}$ & 75 & 15 & 3 & 19,92 & $\overline{2}$ & 15,50 & 3 & 15,50 & $\overline{2}$ & 9,73 & 3 & 19,72 \\
\hline $3(\mathrm{CD})$ & 300 & 10 & 2 & 5,08 & $\overline{2}$ & 9,50 & 3 & 9,50 & 3 & 15,27 & 2 & 5,28 \\
\hline
\end{tabular}

Tabel 16. 


\begin{tabular}{|c|c|c|c|c|c|c|c|c|c|c|c|c|}
\hline \multicolumn{13}{|c|}{ Tabel 16. Lanjưtan } \\
\hline \multirow[b]{2}{*}{ Fipa } & \multirow{2}{*}{$\begin{array}{c}\mathrm{L} \\
\text { (m) }\end{array}$} & \multirow{2}{*}{$\underset{(1 / d / d t)}{Q}$} & \multicolumn{10}{|c|}{$\mathrm{Q}$ (1t/det) } \\
\hline & & & $\begin{array}{c}D \\
\text { (in) }\end{array}$ & $\begin{array}{c}\text { Kasus } \\
1\end{array}$ & $\begin{array}{c}D \\
\text { (in) }\end{array}$ & $\begin{array}{c}\text { Karus } \\
2\end{array}$ & \begin{tabular}{|c|}
$D$ \\
(in)
\end{tabular} & $\begin{array}{c}\text { Kavis } \\
3\end{array}$ & $\begin{array}{c}D \\
\text { (in) }\end{array}$ & $\begin{array}{c}\text { Kasus } \\
4\end{array}$ & $\begin{array}{c}D \\
\text { (in) }\end{array}$ & $\begin{array}{c}\text { Karis } \\
5\end{array}$ \\
\hline $4(\mathrm{BD})$ & 200 & 10 & 2 & 4,64 & 2 & 6,74 & 3 & 6,74 & 3 & 6,39 & 2 & 5,01 \\
\hline $5(\mathrm{AE})$ & 350 & 10 & 2 & 0,28 & 2 & 6,25 & 3 & 6,25 & 3 & 11,65 & 2 & 0,29 \\
\hline$\overline{6(\mathrm{DE})}$ & 80 & 15 & $\overline{2}$ & 3,51 & $\overline{2}$ & 829 & 3 & 829 & $\overline{2}$ & 11,43 & 3 & 2,18 \\
\hline $7(\mathrm{DF})$ & 100 & 5 & 2 & 621 & 2 & 796 & 3 & 796 & 2 & 10,22 & 3 & 8,11 \\
\hline $8(\mathrm{EF})$ & 200 & 5 & 2 & 3,79 & 2 & 2,04 & 3 & 2,04 & 3 & 0,22 & 2 & 1,89 \\
\hline
\end{tabular}

Kesimpulan dari hasil diatas terlihat pada kasus 2 dan kasus 3, dengan menggunakan diameter pipa yang sama akan menghasilkan debit tetap (tidak berubah).

d. Baik secara rumus Hazen Williams maupun rumus Manning, apabila suatu jaringan pipa menggunakan pipa-pipa dengan jenis dan diameter yang sama maka dalam perhitungan $\Delta \mathrm{Q}$, parameter $\left(\mathrm{C}_{\mathrm{HW}}\right.$ atau $\left.\mathrm{n}^{\prime}\right)$ dan (D) dapat saling menghilangkan/meniadakan.

e. Hasil debit yang didapat dengan Metoda Hardy-Cross menurut rumus HazenWilliams dan rumus Manning, pada kasus yang debitnya besar (> 10 lt/det) akan menghasilkan persentasi perbedaan debit ( $\Delta \%$ ) yang tidak jauh berbeda, baik dengan rumus Hazen-Williams maupun rumus Manning, karena persentasi perbedaan debitnya kecil sehingga hasilnya lebih akurat, sebaliknya pada kasus yang debitnya kecil (< 10 lt/det) akan menghasilkan persentasi perbedaan debit $(\Delta \%)$ yang jauh berbeda, baik dengan rumus Hazen-Williams maupun rumus Manning, karena persentasi perbedaan debitnya besar sehingga hasilnya kurang akurat. 
Tabel 17. Debit pada tiap kasus dengan Rumus Hazen-Williams $\left(Q_{\mathrm{HW}}\right)$ dan Rumus Manning ( $\left.\mathbf{Q}_{\mathrm{M}}\right)$.

\begin{tabular}{|c|c|c|c|c|c|c|c|c|c|c|c|c|c|c|c|c|c|c|c|c|c|c|}
\hline \multirow{3}{*}{ Pipa } & \multirow{3}{*}{$\begin{array}{c}\mathrm{L} \\
\text { (m) }\end{array}$} & \multirow{3}{*}{$\begin{array}{l}\mathrm{Q}_{0} \\
\text { (ltid } \\
\text { et) }\end{array}$} & \multicolumn{20}{|c|}{$Q$ (lt/det) } \\
\hline & & & \multirow{2}{*}{$\begin{array}{l}\text { D } \\
\text { (in) }\end{array}$} & \multicolumn{3}{|c|}{ Karus 1} & \multirow{2}{*}{$\begin{array}{c}D \\
\text { (in) }\end{array}$} & \multicolumn{3}{|c|}{ Kasus 2} & \multirow{2}{*}{$\begin{array}{c}D \\
\text { (in) }\end{array}$} & \multicolumn{3}{|c|}{ Kasus 3} & \multirow{2}{*}{$\begin{array}{c}D \\
\text { (in) }\end{array}$} & \multicolumn{3}{|c|}{ Kavus 4} & \multirow{2}{*}{$\begin{array}{c}D \\
\text { (in) }\end{array}$} & \multicolumn{3}{|c|}{ Karus 5} \\
\hline & & & & Qнw & Qix & $\Delta \%$ & & $Q_{\text {HW }}$ & $Q_{m i x}$ & $\Delta \%$ & & Q & $Q_{i r}$ & $\Delta \%$ & & QHW & $Q_{i r}$ & $\Delta \%$ & & QнW & $Q_{i x}$ & $\Delta \%$ \\
\hline $\begin{array}{c}1 \\
(\mathrm{AB})\end{array}$ & 50 & 20 & 3 & 30,47 & 30,28 & 0,63 & 2 & 24,34 & 23,75 & 2.48 & 3 & 24,34 & 23,75 & 2,48 & 2 & 19,07 & 18,35 & 3,92 & 3 & 29,95 & 29,71 & 0,81 \\
\hline $\begin{array}{c}2 \\
(\mathrm{BC})\end{array}$ & 75 & 15 & 3 & 19,99 & 19,92 & 0,35 & 2 & 15,73 & 15,50 & 1.48 & 3 & 15,73 & 15,50 & 1,48 & 2 & 10,10 & 9,73 & 3,80 & 3 & 19,80 & 19,72 & 0,41 \\
\hline $\begin{array}{c}3 \\
(\mathrm{CD})\end{array}$ & 300 & 10 & 2 & 5,01 & 5,08 & 1,38 & 2 & 9,27 & 9,50 & 2.42 & 3 & 9,27 & 9,50 & 2,42 & 3 & 14,90 & 15,27 & 2,42 & 2 & 5,20 & 5,28 & 1,52 \\
\hline $\begin{array}{c}4 \\
\text { (BD) }\end{array}$ & 200 & 10 & 2 & 4,52 & 4,64 & 2,59 & 2 & 6,39 & 6,74 & 5.19 & 3 & 6,39 & 6,74 & 5,19 & 3 & 6,03 & 6,39 & 5,63 & 2 & 4,85 & 5,01 & 3,19 \\
\hline $\begin{array}{c}5 \\
(\mathrm{AE})\end{array}$ & 350 & 10 & 2 & 0,47 & 0,28 & 67,86 & 2 & 5,66 & 6,25 & 9.44 & 3 & 5,66 & 625 & 9,44 & 3 & 10,93 & 11,65 & 6,18 & 2 & 0,05 & 0,29 & 82,76 \\
\hline $\begin{array}{c}6 \\
\text { (DE) }\end{array}$ & 80 & 15 & 2 & 3,26 & 3,51 & 7,12 & 2 & 7,85 & 8,29 & 531 & 3 & 7,85 & 8,29 & 5,31 & 2 & 11,09 & 11,43 & 2,97 & 3 & 1,92 & 2,18 & 11,93 \\
\hline $\begin{array}{c}7 \\
\text { (DF) }\end{array}$ & 100 & 5 & 2 & 6,27 & 6,21 & 0,97 & 2 & 7,80 & 796 & 201 & 3 & 7,80 & 796 & 2,01 & 2 & 9,84 & 10,22 & 3,72 & 3 & 8,13 & 8,11 & 0,25 \\
\hline $\begin{array}{c}8 \\
(E F)\end{array}$ & 200 & 5 & 2 & 3,73 & 3,79 & 1,58 & 2 & 2,20 & 2,04 & 784 & 3 & 2,20 & 2,04 & 7,84 & 3 & 0,16 & 0,22 & 27,27 & 2 & 1,87 & 1,89 & 1,06 \\
\hline
\end{tabular}

f. Disarankan pada penelitian selanjutnya agar jaringan pipa diperluas (diperbanyak jaringannya). Karakteristik pipa yang digunakan lebih bervariasi dan juga menggunakan rumus-rumus lainnya.

\section{DAFTAR PUSTAKA}

1. Bhave, Pramod, R., (1991). Analysis of Flow in Water Distribution Network, Technomic Publishing company Inc., Lancaster, Pennsylvania 17604 USA.

2. Brater, Ernest, F., King, Horace, W., (1976). Handbook of Hydraulics, For the Solution of Hydraulic Engineering Problems, Mc Graw - Hill Book Company, New York.

3. Davis, Calvin, V., Sorensen, Kenneth, E., (1969). Handbook of applied Hygraulics, Third Edition, McGraw-Hill Book Company, New York.

4. Jeppson, Roland, W., (1971). Analysis of Flow in Pipe Network, Ann Arbor Science Publishers Inc., Michigan 48106.

5. Mg Junkin, F.E., Vesilin, P.A., (1968). Practical Hydraulics for The Public Work Engineer, Public Work Magazine, Ridge Wood New Jersey.

6. Potter, Merle, C., (1991). Mechanies of Fluids, Pretience-Hall Inc., New Jersey.

7. Ranald, V. Giles, B.S., M.S. in C.E., (1977) Theory and Problems of Fluids Mechanics and Hydraulics, McGraw-Hill Inc, New York.

8. Triatmodjo, B., (1996). Hidraulika I, Edisi 2, Penerbit Beta Offset, Yogyakarta.

9. Triatmodjo, B., (1993). Hidraulika II, Edisi 1, Penerbit Beta Offset, Yogyakarta. 